\title{
Thought Experiments and Personal Identity in Africa*
}

\begin{abstract}
African perspectives on personhood and personal identity and their relation to those of the West have become far more central in mainstream Western discussion than they once were. Not only are African traditional views with their emphasis on the importance of community and social relations more widely discussed, but that emphasis has also received much wider acceptance and gained more influence among Western philosophers. Despite this convergence, there is at least one striking way in which the discussions remain apart and that is on a point of method. The Western discussion makes widespread use of thought experiments. In the African discussion, they are almost entirely absent. In this article, we put forward a possible explanation for the method of thought experiment being avoided that is based on considerations stemming from John Mbiti's account of the traditional African view of time. These considerations find an echo in criticism offered of the method in the Western debate. We consider whether a response to both trains of thought can be found that can further bring the Western and African philosophical traditions into fruitful dialogue.
\end{abstract}

KEYWORDS: person, personal identity, time, thought experiments, African philosophy

\section{Introduction}

African perspectives on personhood and personal identity and their relation to those of the West have become far more central in mainstream Western discussion than they once were. Not only are African traditional views with their emphasis on the importance of community and social relations more widely discussed, but that emphasis has also received much wider acceptance and gained more influence among Western philosophers (see, for example, Schechtman 20I4; Baker 20I5; Helm 2017). Despite this coming together, there is at least one striking way in which the discussions of persons and personal identity remain apart, and that is on a point of method. The Western discussion makes widespread use of thought experiments; they may well be more common here than in any other field of philosophy and have featured in the cases offered on behalf of every live theory in the debate. In the African discussion, they are almost entirely absent. In this article, we investigate the possible philosophical reasons behind this difference and draw out their implications. Ultimately, we argue that while there are independent

\footnotetext{
*This article is the eighth in a special series of commissioned articles on non-Western philosophies. The seventh article, 'Eliminating Selves and Persons', by Monima Chadha, appeared in Volume 7, Issue 3, pp. 273-294.
} 
reasons within African philosophy for skepticism about radically counterfactual thought experiments, it also contains the philosophical resources to cope with them.

The method of thought experiment in the Western personal identity debate has a long history, going back to John Locke's seminal discussion that began its modern version. Locke asked his readers to imagine the soul of a prince, taking with it the prince's 'consciousness', going in to a (soul-free) cobbler's body and then asked who we would say the resulting person was as part of his case for the view that personal identity was not a matter of body or soul identity, but one of sameness of consciousness (Locke I975: 340). Appeals to imagined scenarios have continued to characterize the debate up until the present, with notable examples like that of Derek Parfit considering the consequences for the concept of personal identity of one person splitting into two or of one person being gradually turned into the replica of another person (Parfit I984: 236-65). Although highly influential, this argument strategy has not found favor with all in the debate and we will return to criticism later.

There is no such explicit criticism to be found in the African debate. But there are (almost) no thought experiments either. There is, as in the Western debate, appeal to examples in literature, but even this is uncommon on the African side and far less frequent than in the West. Reservations about the method are not set out, but are shown by its being avoided. Conversations with African philosophers reveal no specific considered theoretical point of departure, other than the suggestion that the approach is 'un-African'. In this gap, we tentatively put forward an explanation for the method of thought experiment being avoided that is based on considerations stemming from John Mbiti's account of the traditional African view of time.

\section{Mbiti, Time, and Counterfactual Thought}

Views on time may sound far removed from views on personal identity and philosophical method, but Mbiti suggests that the African view of time is 'key to our understanding of the basic religious and philosophical concepts' (Mbiti I990: I6) and what he has to say on the topic has fairly clear resonance with our issue. In fact, it can be the starting point of an explanation for the unpopularity of thought experiment in African discussions on personhood and personal identity. Mbiti points to how different African views of time are from Western ones: 'time is a two-dimensional phenomenon, with a long past, a present and virtually no future. The linear concept of time in western thought, with an indefinite past, present and infinite future, is practically foreign to African thinking' (Mbiti I990: I6-I7).

We think that implicit in the different views on time Mbiti refers to is a difference in perspective on the world. This is because Mbiti goes on to explain that African time flows backward, implying that the most significant dimension of time is the past. It is easy to see from here why the use of thought experiments, especially those like Parfit's that imagine conditions that could only be achieved in the future, present a special challenge.

To appreciate fully why Mbiti's conception of time forecloses counterfactual thinking, specifically the kind we see in the use of thought experiments, we have to look closely at what he actually says about time. He writes, 'time is simply a 
composition of events which have occurred, those which are taking place now and those which are inevitably or immediately to occur. What has not taken place or what has no likelihood of an immediate occurrence falls in the category of "No-time". What is certain to occur, or what falls within the rhythm of natural phenomena, is in the category of inevitable or potential time' (I990: I6, our emphasis).

As we read him, part of what Mbiti means is that time is inseparable from actual or potential events. It is neither the container of events nor the mere order of their succession. It is also not the frame through which events are imagined. It is the events themselves - of the past, present and immediate future. Mbiti's view is that events define time in the same way content defines space (I990: 26). These assumptions about time are at odds with those built into the use of thought experiments in philosophical debates. In fact, that there is enormous flexibility in constructing them is in part because their users assume not only that events are independent of time but also, crucially, that 'empty' time can be populated by whichever counterfactual scenarios can do the required work. As far as Mbiti is concerned, their entire operation falls in the category of 'No-time'. To our minds, this seems to imply that some of the events they attempt to describe are simply not intelligible.

Where this view becomes of even greater interest to us is with regard to the distant future and remote events, because such events are not intelligible. In other words, events that are far removed from experience are ones that people are not able to make sense of. Mbiti points to this explicitly: 'Since what is the future has not been experienced, it does not make sense; it cannot, therefore, constitute part of time, and people do not know how to think about it-unless, of course, it is something which falls within the rhythm of natural phenomena' (I990: I7).

Precisely what thought experiments like Locke's prince and cobbler case present are events that are distantly removed from our experience. We do not and have not come across body-swaps, nor do they have any immediate likelihood of occurring. They certainly do not 'fall within the rhythm of natural phenomena', which for Mbiti also implies that they are not intelligible. As such, not only are they not able to find a place in African discussions on personhood and personal identity, they simply will not be able to do the work philosophers require them to do. As Souleymane Bachir Diagne explains, for Mbiti, 'to think of a future event entails a veritable contradiction' (2016:38).

The concern is not just about events that are set in some imagined remote future. We have already alluded to doubts about the possibility of remote events, but here he takes it further, expressing a deep skepticism regarding progress. In what is perhaps his most contentious and unsettling claim, Mbiti says that because 'the centre of gravity of human thought. . . lies in the past,' African peoples not only 'have no belief in progress,' they also resist the urge to 'build castles in the air' (I990: 23). This has the implication that thought experiments, in particular those that rely on technological fictions about scientific progress, are on even shakier grounds. They purport to illuminate philosophical debates by describing scenarios whose acceptability depends on scientific and technological progress. However, they are 
unlikely to elicit the required responses if those to whom they are addressed have a conception of time that prevents them from having such a belief.

Moreover, Mbiti suggests that his African conception of time is reflected in the form of the language, in that 'the languages themselves have no verb tenses to cover that distant "future" dimension of time' (I990: 2I-22). Instead, one typically finds that references to time track real life experiences and events, resulting in what Mbiti calls 'phenomenon calendars', which he contrasts with 'numerical' calendars. One example is from the Otuho language of the Latuka people, in which 'the heat of the sun' describes the month of October (Mbiti I990 I7). And, adding to Mbiti's linguistic point, the languages to which he refers (in particular Kikamba and Kikuyu) that have no distant future tense also have no formal subjunctive mood. Indeed, there is no such formal mood in many, even most, sub-Saharan African languages. Counterfactuals are expressed in these languages, but in indicative form using the context to convey the counterfactual nature of the claim. (Timothy Williamson has argued that thought experiments are disguised counterfactual judgments [2007: 179-207]. Even those who do not accept Williamson's analysis will agree that many of the most important cases in the literature involve counterfactual reasoning in some integral way.) In line with Mbiti's thought, scenarios far removed from past experience would be unlikely to find such expression and would be (at least on the face of things) difficult to describe meaningfully. Attempts to translate counterfactual claims directly into sub-Saharan African languages come out sounding strange and have the tone of a command, easily taken to be rude and against the spirit of Ubuntu. (Ubuntu is an umbrella term for a range of values, including humaneness, solidarity, harmony, that is prominent in sub-Saharan African cultures, and especially among the Bantu-speaking peoples of Southern Africa. For various characterizations of the idea, see Tutu [1999]; Ramose [1999]; Metz [2007].) As a result, they may be even more difficult to use as part of persuasive arguments.

In making these observations, we do not mean to suggest that Mbiti's conception of time excludes all forms of counterfactual thinking. On the contrary, the conception allows for people to think counterfactually in ordinary interactions. For example, after a rich harvest, a farmer in a region plagued by frequent droughts would rather store up yams in his barn to stave off a potential famine. Grivas Kayange provides an example of Chichewa speakers in Malawi, which applies more widely to speakers of sub-Saharan African languages, using causal statements to express conditionals, communicate counterfactual scenarios and thereby impress on others, especially children, what would happen if they took some course of action or other. 'If $\mathrm{x}$ eats immature mango, then $\mathrm{x}$ develops mumps', children will be told even though $\mathrm{x}$ has not eaten mango. This might well be translated in counterfactual form ('If $\mathrm{x}$ had not eaten mango, $\mathrm{x}$ would not have developed mumps'), even though the conditional is indicative, since it reflects counterfactual reasoning (Kayange 20I8: 45). Such kinds of reasoning, however, would involve possible scenarios that are entailed by or have an organic link to events that have already occurred or are now unfolding. Unlike the extreme forms of counterfactual thinking and farfetched scenarios seen in certain thought experiments, these ones fall within the realm of Mbiti's potential time. 
We also acknowledge that in the absence of a widespread written tradition in sub-Saharan Africa, characterizations of the quintessential African village by African philosophers, as part of a broader endeavor in writing the sociological history of Africa, may be seen as exercises in counterfactual thinking. ${ }^{\mathrm{I}}$ But, again, these attempts, and the experiences and events characteristically attributed to the African village, do not fall outside the realm of experience. They are compatible with much of what Mbiti says about time.

It is worth noting at this point that the most prominent African account of personhood and personal identity, namely that put forward by Ifeanyi Menkiti, is entirely approving of Mbiti's view of time. Menkiti draws attention to the relationship between his maximal concept of person and the two-dimensional view of time-that is, the view according to which there is no distant futurewhen he claims that 'time's movement', in traditional African thought, 'was generally from the present to the past, so that the more of a past one has, the more standing as a person one also has' (2004: 325$)$. And as if to make a more explicit point about method and jettison any attempt at counterfactual thinking, he goes on to say that the 'empirical temperament, or attitudinal posture' of traditional Africans was toward those things that are familiar and validated by experience. 'One goes by known things,' he writes, 'by the flow of time that has occurred, not the flow of time to occur' (Menkiti 2004: 329).

There is thus a case to be made for a theoretical underpinning of the un-Africanness of thought experiments offering an explanation of their scarcity in the African philosophy literature. The one discussion in which they do make an explicit appearance seems to offer some confirmation for this theory: Leke Adeofe says of the kind of body-swap scenario described by Locke that 'there are serious difficulties imagining this kind of exchange' (Adeofe 2004: 73). We discuss the details of Adeofe's contribution later.

\section{An Echo in the Western Debate}

The explanation we are offering raises important issues of epistemic injustice since it implies 'an unwarranted infringement on the epistemic agency of knowers', which is how Kristie Dotson characterizes epistemic oppression (2014: II5). Just as the futural dimension of time was imposed on Africans from outside (as Diagne (20I6: 4I) reads Mbiti to be saying), to call for the use of thought experiments seems to amount to an alien method of doing philosophy being imposed. There may indeed be reasons for seeing this as an even more insidious form of epistemic injustice. These stem from the fact that there is a significant trend in the Western debate on personal identity itself that questions the method of thought experiment on grounds that appear to echo Mbiti's words in significant ways. We find objections to the effect that the thought experiments of Locke and Parfit ask us to make judgements that we are in no position to make, or present situations in which our words and concepts have no meaningful purchase. The grounds of criticism vary, but there is a common theme of complaint that the envisaged scenarios are too far

\footnotetext{
${ }^{\text {I }}$ We are grateful to Ndumiso Dladla for alerting us to this point.
} 
removed from our actual circumstances and experiences for our responses to them to have any significance or authority. Below we briefly consider this trend.

In his Self-Knowledge and Self-Identity, Sydney Shoemaker (I963) presents a case for us to imagine: Brown and Robinson undergo a brain transplant, each receiving the brain of the other. Brown dies immediately after the operation; Robinson's body with Brown's brain, survives. He is dubbed 'Brownson'. Brownson has all of Brown's memories, personality traits, and desires and intentions, and many report the intuitive response that Brownson is Brown and take this as reflecting that a Lockean theory underlies our concept of person and personal identity. But Shoemaker was wary of drawing the conclusions that seemed to most Western commentators to be obvious in response to the thought experiment. He held that the criteria people currently use to judge personal identity are predominantly physical ones, and that these are adequate for dealing with the situations they encounter. As far as the case of Brownson is concerned, since its kind has never been encountered, there is no established response to be made:

The question of what most people would say if the imagined events occurred is of course a factual question, and not a question for philosophers to decide. But something can be said, of a philosophical nature, about what would be the case if such events were to happen and if nearly everyone were to agree that a change of body had taken place. First, it clearly cannot be said that in making this judgement people would be mistaken; at most it can be said that in making it they would show that they had adopted new criteria of personal identity and that their judgement would not be in accord with our present criteria. (Shoemaker I963: 246, emphasis Shoemaker's)

Shoemaker is by no means alone in his circumspect treatment of such cases. One of the most forceful statements of relevant considerations, and an influential argument against the use of thought experiments to reach conclusions about personal identity, came nearly twenty-five years later from Antony Flew:

[W] ought never to forget, what almost always in the present context has been forgotten, that there is a categorical difference between fact and fiction. Our notions both of persons and personal identity evolved in adaptation to the actual situations in which our ancestors found themselves; and they will no doubt continue to evolve if and in so far as our actual situations become in relevant ways drastically different. But considerations of how in future we either ideally should or in fact would alter these or other concepts, were we in truth confronted by this or that unquestionably conceivable yet way-out fantastic predicament, are simply not relevant to investigations of the present meanings either of the word 'person' or of the expression 'same person'. (Flew 1987: I23) 
Flew's words express thoughts similar to those underlying Shoemaker's discussion. Like Shoemaker, Flew is in effect ruling out all the thought experiments that have become staples of the personal identity debate in Western philosophy.

The wariness of Shoemaker and Flew stems from the fact that apparent body-swaps like that described do not actually occur and the belief that only our responses to actual situations can be an index of the meaning of our words. Unlike Mbiti, they accept that these distant scenarios are imaginable, but like Mbiti they contend that we do not know how to think about them. By contending that consideration of situations that we do not or have not encountered is irrelevant to the meaning of the expressions we use, Flew argues on grounds that echo Mbiti that no interesting counterfactual thought experiment has any place in philosophical methodology.

Kathleen Wilkes launched one of the most influential attacks on the thought experiments central to the Western debate in her book Real People (subtitled Personal Identity without Thought Experiments), and she raised similar concerns (Wilkes I988: I-2I). She suggests that any such envisaged counterfactual phenomenon as the case of a person splitting into two would need a mass of information before the phenomenon could be 'established' and before we can understand whether our concepts of person and personal identity apply: 'It is obviously and essentially relevant to the purposes of this thought experiment to know such things as: how often? Is it predictable? Or sometimes predictable and sometimes not, like dying? Can it be prevented? Just as obviously, the background society, against which we set the phenomenon is now mysterious. Does it have such institutions as marriage? How could that work? Or universities? It would be difficult, to say the least, if universities doubled in size every few days, or weeks, or years. Are pregnant women debarred from splitting? The entire background here is incomprehensible' (Wilkes I988: I I, emphases Wilkes's).

With the details changed, similar complaints could be raised against Locke-type 'body transfers'. More recently, Marya Schechtman has expressed reservations of the same kind: 'it is not evident that the worlds depicted are sufficiently like ours to tell us anything about persons as we know them' (Schechtman 20I4: I 54). Her argument is that we may not realize how the counterfactual phenomenon being proposed may interfere with the social engagements that are constitutive of the concept, and so we do not really understand what we are responding to.

The theme of all these arguments is that thought experiments ask us to make judgments that we are in no position to make. Just as Mbiti said about the distant future in traditional African thought, people do not know how to think about the things they require us to think about.

There are two concerns about the dangers in doing comparative philosophy that this brief discussion of a theme in the Western debate may answer. One is that, in setting out how African thought differs from Western thought, you may play into the hands of Africa's colonizers and reflect African thinking as irrational simply because it is different. The other is the danger of making the mistake Kwasi Wiredu (I998) warns against: comparing traditional African thought, to its detriment, to contemporary Western thought when it is the traditional thought of any culture that should be compared with the traditional thought of Africa. The 
discussion so far, however, is not to the detriment of the traditional view of time described by Mbiti and its implications for thought experiments. Far from that, it reflects the distinctive rationality within the traditional African view and finds a supportive echo in another tradition of philosophical thinking.

\section{Back to Mbiti on Time and Its Implications for Thought Experiment}

While this might seem to some a convenient point to end the discussion, we see four reasons for not stopping here. One is that Mbiti acknowledges that African thought is not static and bound by its past. He is open to the future dimension of time being appropriated by Africans: 'African peoples are discovering the future dimension of time.. . . The discovery and extension of the future dimension of time possess great potentialities and promises for the shaping of the entire life of African peoples. If these are harnessed and channelled into creative and productive use, they will no doubt become beneficial' (Mbiti I990: 27). Likewise, even if thought experiments were not part of the traditional debate, the method could be appropriated by African thinkers.

This leads to a second reason, one that begins to address the issue of epistemic injustice. It concerns the accuracy of Mbiti's account of the African view of time and thoughts that stem from a discussion of it. Mbiti himself asked that those who disagree with him on African time should provide appropriate African counterexamples-a challenge that Kwame Gyekye (I987) has met by demonstrating that 'three-dimensional time', incorporating a distant future, is an acknowledged feature of the Akan conceptual scheme. D. A. Masolo and Diagne have made similar points in relation to the Luo and Wolof languages of eastern and western Africa respectively (Masolo I994: I I 8-I9; Diagne 2016: 42). (In our own South African context, the Zulu word Kusasa refers to tomorrow or the immediate future, and iksasa refers to an indefinite future, corroborating observations in other parts of Africa.) Masolo examines certain Luo proverbs that seem to point to a conception of time that extends into the distant future (I994: I I 8-I9). Diagne argues that there is no reason at all to think that the Wolof word $\ddot{e} l l e \ddot{g}$, which is the equivalent of demain in French and tomorrow in English, does not entail an indefinite future (2016: 42). These counterexamples are powerful reminders both that we should not hastily generalize about Africans (or any large group of people for that matter) on the basis of a limited set of data and that we need not concede the thought that a conception of time entailing an indefinite future is a colonial imposition.

We also think there is something to be said about Mbiti's own analysis of time, in particular his example from the Swahili language, and whether it succeeds in showing that a two-dimensional view of time comes naturally to the speakers of that language. The concern for us is whether Mbiti is correct in assuming that language in general, or some African language in particular, is a reliable route to metaphysics. We understand from Diagne that the Swahili words for past and present, zamani and sasa respectively, upon which much of Mbiti's analysis is based, have their origin in Arabic and are related to jamano and saa in his native 
Wolof. He goes on to say that although in these two languages the future dimension of time remains in the use of zamani, it seems to have disappeared in usage among the people who are the focus of Mbiti's analysis. For Diagne, and for us, the lesson is quite clear: 'no word is in itself the proof of an African conception of time for which only the concrete past and present exist, and of which it would be the natural expression' (Diagne 20I6: 44). Like Diagne we wonder whether the realization that words do not have a 'natural concrete sense' should perhaps lead us to question 'the thesis that the future dimension of time came to Africans from the outside' (Diagne 20I6: 44). As the usage of zamani in Arabic and Wolof shows, they can be adapted to different contexts.

What the above implies for our present purposes is that the use of thought experiments cannot be simply ruled out as a viable method in African philosophical practice on the grounds that it is a colonial imposition. We do, however, acknowledge in general the challenge of Western conceptual imposition. Consideration of this leads to a different approach in the work of Wiredu. It concerns what we can realistically do in response to the real threat of conceptual colonization and imposition. Wiredu recommends the practice of what he terms 'due reflection' as an approach to 'conceptual decolonization.' He means both that we should develop 'a critical conceptual self-awareness' so as to prevent 'unexamined assimilation in our thought . . . conceptual frameworks embedded in the foreign philosophical traditions that have had an impact on African life and thought' and that we exploit 'the resources of our indigenous conceptual schemes in our philosophical meditations' (Wiredu I995: I36).

We think that the merit of Wiredu's approach is that it allows the practice of African philosophy to be open to approaches that may have been useful in other traditions of philosophy. Moreover, there are immense benefits for intercultural philosophy. As Wiredu says, if we apply, 'due reflection, being always on the lookout for any conceptual snares, perhaps we can combine insights extracted from those sources with those gained from our own indigenous philosophical resources to create for ourselves and our peoples modern philosophies from which both the East and the West might learn something' (Wiredu I995: 2I).

The third reason relates to the first two. It is based on the evidence of imaginative counterfactual thought to be found in contemporary African literature, specifically in the growing appreciation of the science fiction genre in Africa (Okorafor 2009). Other African writers, such as Wanuri Kahiu, Kojo Laing, Emmanuel Dongala, and Lesley Arimah, to name a few, are also part of this recent trend.

While acknowledging the relative absence of the genre in African literature, Nnedi Okorafor thinks that African 'palettes will grow accustomed to and hopefully even crave home-grown African-rooted science fiction' (Okorafor 20I4). More directly to the point, there is evidence from the one extended discussion in African philosophy of personal identity. (For a more recent attempt to incorporate thought experiment in African discussion of personhood, see Oyowe [2018].) Above we referenced Adeofe's concerns regarding a scenario like Locke's prince and cobbler thought experiment. But Adeofe goes on to provide an African perspective on just such an imaginary scenario. His complaints (it emerges) concern not the issue of counterfactual imagination itself but rather the issue of whether Locke has the 
metaphysical wherewithal to get his experiment off the ground. Adeofe suggests that African thought stands to provide just that. The fourth and final reason for continuing the discussion is that there are grounds-from both within and outside of African philosophy-for being dissatisfied with the criticisms of the method of thought experiment described above. We discuss some of these below; others can be found in Beck (20I4, 2016).

\section{Adeofe's Contribution}

Adeofe describes his enterprise as fitting in with the approach of Locke, being 'partly descriptive and partly imaginative' (Adeofe 2004: 69). He outlines the sort of thought experiment that Locke indulged in, in which a soul or brain is transferred from one body into another (his actors are 'Adler' and 'John' rather than the prince and the cobbler) and criticizes the responses of various Western theories to this situation. The Cartesian is misguided in seeing our concern with personal identity as being concern for the soul, whereas it is concern for our 'psychic unity' (2004: 79). Lockeans may be closer to getting this right, but still fall short. They sever the link between what we are and our persistence: 'our persistence is about us and ought to preserve our whatness' (2004: 75-76, emphasis Adeofe's). Locke requires sameness of consciousness for personal identity but plays down 'what we are'; according to his metaphysics we are bodies and souls, but neither sameness of body nor soul is required for personal identity in his account. The Lockean's (as does the Cartesian's) solution 'violates our organic nature' (Adeofe 2004: 80). Adeofe is not ruling out that a body-swap is conceivable, however; his concern is that Locke's judgment that the prince and the cobbler have swapped bodies-in the circumstances he describes-is inconsistent with a deep metaphysical principle. (The circumstances Locke describes, according to Adeofe [2004: 72], are those of a brain-transfer taking psychology with it. It seems clear from Locke's text [1975: 340] that Locke envisages a soul as the carrier-across of the prince's consciousness rather than a brain; but this can still be seen as destroying the organic nature of a complete human in the sort of way Adeofe is criticizing.)

This is where African metaphysics offers a telling alternative. For the metaphysics of the Yoruba, which finds echoes in the metaphysics of other African cultures, such as that of the Akan described by Gyekye (I992), is a tripartite conception of the person that offers a different possibility. It recognizes ara (body) and emi (roughly mind or soul) but includes the additional part of ori (literally inner head, but embodying personality and more). Emi and ori are both mental (or spiritual) but are independent parts of the person. Human identity is a matter of the persistence of emi and ara, and this leaves it open that the organic nature of the human can be preserved while we imagine the ori of Adler being transferred into the organically intact human John (without John's ori) (Adeofe 2004: 78).

Adeofe acknowledges that the Lockean, as he has characterized Lockean thinking, would see this as the transfer of a person, but (according to Adeofe) would do so for the misplaced reason that the John-person now has Adler's projects and is capable of fulfilling Adler's social roles. (It may be that there is a school of African thought more along the lines that Adeofe characterizes as 
Lockean here, than are those he characterizes as African. The traditional view of personhood described by Menkiti highlights performance of the obligations expected of an individual by the community, that is, social role, as the mark of personhood and, by implication, personal identity [Menkiti I984]. To show that the Lockean is wrong, Adeofe really needs another thought experiment to which we would respond differently from the dictates of the Lockean theory. This is left implicit in his essay.) The African thought is that it is a transfer because 'John now has the characteristic fortunes (or misfortunes) defining Adler's former life' (2004: 79). By contrast, the Lockean who stresses the importance of psychological continuity sees the John-body-person as Adler because this person will have Adler's projects, but it is a mistake to take identity as a matter of whoever can fulfil that set of projects. This would be to mistake the real concern of personal identity: 'The concern with the continuity of our intentions, beliefs, and memories is a concern not with specific projects but with the successful completion of whatever projects there are, as long as they contribute to our self-actualization' (Adeofe 2004: 80).

This is important for Adeofe, because Adler's ori together with John's ara and emi could complete either Adler's or John's projects, yet the person doing so would be Adler. It is not the projects that make the person Adler, but that whatever projects he is involved in are fulfilled according to Adler's chosen destiny. We use Adeofe's own words to make this clearer:

To sharpen the example, assume the following: Adler's former life had been enviable. His desires were nicely moderated. He was successful in friendships, business, health, and in his communal relations. He could hardly do anything wrong. John's former life was the exact opposite. He failed consistently in his endeavors. His sincere and worthy efforts to succeed and be perceived differently came to naught. Indeed, John was not doing anything substantially different from what Adler was doing, but the outcome for John had been consistently bad, and for Adler consistently good. Africans would ascribe the disparities in results to their choices of ori. If we now suppose an exchange of ori between Adler and John, we would expect John's life to be consistently worthwhile and admirable, and Adler's life consistently the opposite. (Adeofe 2004: 79)

If such a change in destiny is what the details of the thought experiment reflect, then the judgment that there had been a person transfer would, according to Adeofe, be correct.

Adeofe's discussion provides us with no reason to reject thought experiments as un-African, far from it. His thought experiment is distinctly African in its reliance on Yoruba metaphysics and his use of it shows that thought-experimental arguments can be regarded as a bona fide African practice. Nor does it provide support to the skeptical arguments that we canvassed earlier. It illustrates that our concepts can and do extend beyond the specific circumstances in response to which they developed, a truth emphasized by the way in which all imaginative fiction gets understood. Wilkes (I988) implies that the social background needed to 
understand whether our concept applies cannot be provided in the case of a phenomenon like splitting or body transfer, but that does not seem to be a fair contention. Adeofe's discussion indicates a more reasonable requirement-that for someone to respond positively to a thought experiment, enough social information needs to be specified for them to be comfortable in applying the concept in question. Adeofe points out how specifying the social roles fulfilled by the protagonists or specifying their projects will help, even though he thinks that may not be enough. (Of course, it may also be more than enough. Others might respond by applying a concept to a scantily described scenario with ease.) The point of using a thought experiment can still be the same one that Locke had in mind: the thought experiment will provide a scenario in which the concept in question is applied when some theory says that it does not or cannot apply, and so we get closer to understanding the conditions underlying the concept's application.

Looking at the thought experiment Adeofe offers, it becomes clear that he envisages both Lockeans and those who share his African view presenting the same judgment (2004: 78-79). The thought experiment does not select between their theories and he has to offer other considerations to press the case for his explanation of the correctness of the judgment over theirs. But both can agree that personal identity is not ultimately a matter of ara and emi persistence, and that is shown by their response to his scenario. In turn, you may wish to put pressure on various claims to necessity that Adeofe makes, and a thought experiment (carefully crafted) might be just the way to do so.

\section{Conclusion}

Some important questions raised earlier remain unanswered in the discussion so far. Adding to Mbiti's point about sub-Saharan African languages that have no expressions for a distant future dimension of time, we pointed out that they also lack a subjunctive form. Adeofe's African thought experiment is expressed in English. This sidesteps one problem but raises others: the injustice would appear to remain if Africans are required to philosophize in English about personal identity should they wish to use thought experiments. There is an ongoing debate about the language of African philosophy, strongly sensitive to issues related to this one, and especially the role of colonial languages in entrenching Western concepts. (On the debate about the language of African philosophy see Fayemi 2013; Bewaji 2002; Keita I999; Tangwa I999; Bello I987.) We do not have an original contribution to that debate, but we do think the linguistic problem posed by the counterfactual form of thought experiments is easy to overstate. Doing so in English is not the only option for African philosophers who wish to use thought experiments. (We are not denying that there are other postcolonial pressures to philosophize in English, but that is a different dimension from the one we are discussing.) As we noted above, counterfactual claims do get expression in the languages discussed by using claims in the indicative form and relying on context to show their mood. This may sound like a route to confusion, but in practical terms that confusion does not arise. Consider an example (not a counterfactual, but one on the face of things far more likely to lead to confusion). 
In the Bemba language spoken in Zambia the word for tomorrow is mailo, which is the same as the word for yesterday. To an English speaker this may sound like a direct route to paradox, but there is no confusion among Bemba hearers as to which day the speaker means when they use the term. ${ }^{2}$ In the same way, the absence of an equivalent for the verb form would provides no grounds for any conclusion that African thinkers cannot use counterfactual scenarios. There will be problems that may be extremely difficult to overcome for those who attempt to translate thought-experimental arguments directly from English into one of these languages, but that is a set of problems different from ours.

There is room for thought experiments in African philosophy especially in the discussion of personhood and personal identity. They can be employed meaningfully in ways that do not impose alien forms of thinking and that can further bring the Western and African philosophical traditions into fruitful dialogue.

SIMON BECK (D)

UNIVERSITY OF THE WESTERN CAPE sbeck@uwc.ac.za

ORITSEGBUBEMI ANTHONY OYOWE UNIVERSITY OF THE WESTERN CAPE ooyowe@uwc.ac.za

\section{References}

Adeofe, Leke. (2004) 'Personal Identity in African Metaphysics'. In Lee M. Brown (ed.), African Philosophy: New and Traditional Perspectives (Oxford: Oxford University Press), 69-83.

Baker, Lynne Rudder. (20I5) 'Human Persons as Social Entities'. Journal of Social Ontology, I, 77-87. Beck, Simon. (20I4) 'Transplant Thought Experiments: Two Costly Mistakes in Discounting Them'. South African Journal of Philosophy, 33, 188-199.

Beck, Simon. (2016) 'Reconsidering a Transplant: A Response to Wagner'. South African Journal of Philosophy, 35, I32-40.

Bello, A. G. A. (I987) 'Philosophy and an African Language'. Quest, I, 5-I I.

Bewaji, John. (2002) 'African Languages and Critical Discourse'. In Olusegun Oladipo (ed.), The Third Way in African Philosophy: Essays in Honour of Kwasi Wiredu (Ibadan: Hope Publications), 27I-95.

Diagne, Souleymane Bachir. (20I6) The Ink of the Scholars: Reflections on Philosophy in Africa. Translated by Jonathan Adjemian. Oxford: Council for the Development of Social Science Research in Africa.

Dotson, Kristie. (20I4) 'Conceptualising Epistemic Oppression'. Social Epistemology, 28, I I 5-38. Fayemi, Ademola Kazeem. (20I3) 'The Problem of Language in Contemporary African Philosophy'. Inkanyiso: Journal of Human and Social Sciences, 5, I-I I.

Flew, Anthony. (1987) The Logic of Mortality. Oxford: Blackwell.

Gyekye, Kwame. (1987) An Essay on African Philosophical Thought: The Akan Conceptual Scheme. New York: Cambridge University Press.

Gyekye, Kwame. (I992) 'Person and Community in Akan Thought'. In Kwasi Wiredu and Kwami Gyekye (eds.), Person and Community (Washington, DC: Council for Research in Values and Philosophy), IOI-22.

\footnotetext{
${ }^{2}$ We are grateful to the multilingual expertise of Felix Banda and M. John Lamola in guiding us on matters of usage.
} 
Helm, Bennett. (2017) Communities of Respect: Grounding Responsibility, Authority, and Dignity. Oxford: Oxford University Press.

Kayange, Grivas Muchineripi. (2018) Meaning and Truth in African Philosophy: Doing African Philosophy with Language. Cham: Springer.

Keita, Lansana. (I999) 'Africa and Its Linguistic Problematic'. Quest, I3, 27-35.

Locke, John. [1694] (1975) An Essay Concerning Human Understanding. Edited by Peter Nidditch. Oxford: Oxford University Press.

Masolo, D. A. (1994) African Philosophy in Search of Identity. Bloomington: Indiana University Press.

Metz, Thaddeus. (2007) 'Toward an African Moral Theory'. Journal of Political Philosophy, I 5 , $32 \mathrm{I}-4 \mathrm{I}$.

Mbiti, John S. (1990) African Religions and Philosophy. 2nd ed. Oxford: Heinemann.

Menkiti, Ifeanyi A. (1984) 'Person and Community in African Traditional Thought'. In Richard A. Wright (ed.), African Philosophy: An Introduction, 3rd ed. (Lanham: University Press of America), I7I-8I.

Menkiti, Ifeanyi A. (2004) 'On the Normative Conception of a Person'. In Kwasi Wiredu (ed.), A Companion to African Philosophy (Malden: Blackwell), 324-3 I.

Okorafor, Nnedi. (2009) 'Is Africa Ready for Science Fiction?' Nnedi's Wahala Zone Blog. August I2, 2009. http://nnedi.blogspot.com/2009/08/is-africa-ready-for-science-fiction.html?view=timeslide.

Okorafor, Nnedi. (20I4) ‘African Science Fiction Is Still Alien'. Nnedi’s Wahala Zone Blog. January I 5 , 2OI4. http://nnedi.blogspot.com/2OI 4/O I/african-science-fiction-is-still-alien.html?view=timeslide.

Oyowe, Oritsegbubemi Anthony. (2018) 'Personhood and the Strongly Normative Constraint'. Philosophy East and West, 68, 783-80I.

Parfit, Derek. (1984) Reasons and Persons. Oxford: Clarendon Press.

Ramose, Mogobe B. (1999) African Philosophy through Ubuntu. Harare: Mond Books.

Schechtman, Marya. (20I4) Staying Alive: Personal Identity, Practical Concerns, and the Unity of a Life. Oxford: Oxford University Press.

Shoemaker, Sydney. (1963) Self-Knowledge and Self-Identity. New York: Cornell University Press.

Tangwa, Godfrey. (I 999) 'Colonialism and Linguistic Dilemma in Africa: Cameroon as a Paradigm'. Quest, I3, 3-17.

Tutu, Desmond. (1999) No Future without Forgiveness. New York: Random House.

Wilkes, Kathleen V. (I988) Real People: Personal Identity without Thought Experiments. Oxford: Clarendon Press.

Wiredu, Kwasi. (1995) Conceptual Decolonization in African Philosophy: Four Essays. Ibadan: Hope Publications.

Wiredu, Kwasi. (I998) 'How Not to Compare African Thought with Western Thought'. In Emmanuel Chukwudi Eze (ed.), African Philosophy: An Anthology (Oxford: Blackwell), I93-99. 